\title{
An improved similarity-based approach to predicting and mapping soil organic carbon and soil total nitrogen in a coastal region of northeastern China
}

\author{
Shuai Wang ${ }^{1,2,3}$, Kabindra Adhikari ${ }^{4}$, Qianlai Zhuang ${ }^{3}$, Zijiao Yang ${ }^{1}$, Xinxin Jin ${ }^{\text {Corresp., } 1}{ }^{,}$,iubing Wang ${ }^{1}$, Zhenxing \\ Bian $^{1}$ \\ ${ }^{1}$ College of Land and Environment, Shenyang Agricultural University, Shenyang, Liaoning, China \\ 2 Key Laboratory of Ecosystem Network Observation and Modeling, Institute of Geographic Sciences and Natural Resources Research, Chinese Academy \\ of Sciences, Beijing, China \\ 3 Department of Earth, Atmospheric, and Planetary Sciences, Purdue University, West Lafayette, Indiana, United States of America \\ 4 Grassland, Soil and Water Research Laboratory, USDA-ARS, Temple, United States of America \\ Corresponding Author: Xinxin Jin \\ Email address: jinxinxin0218@syau.edu.cn
}

Soil organic carbon (SOC) and soil total nitrogen (STN) are major soil indicators for soil quality and fertility. Accurate mapping SOC and STN in soils would help both managed and natural soils and ecosystem management. This study developed an improved similaritybased approach (ISA) to predicting and mapping topsoil (0-20 cm soil depth) SOC and STN in a coastal region of northeastern China. Six environmental variables including elevation, slope gradient, topographic wetness index, the mean annual temperature, the mean annual temperature, and normalized difference vegetation index were used as predictors. Soil survey data in 2012 was designed based on the clustering of the study area into six climatic vegetation landscape units. In each landscape unit, 20-25 sampling points were determined at different landform positions considering local climate, soil type, elevation and other environmental factors, and finally 126 sampling points were obtained. Soil sampling from the depth of $0-20 \mathrm{~cm}$ were used for model prediction and validation. The ISA model performance was compared with the geographically weighted regression (GWR), regression kriging (RK), boosted regression trees (BRT) considering mean absolute prediction error (MAE), root mean square error (RMSE), coefficient of determination $\left(R^{2}\right)$, and maximum relative difference (RD) indices. We found that the ISA method performed best with the highest $\mathrm{R}^{2}$ and lowest MAE, RMSE compared to GWR, RK, and BRT methods. The ISA method could explain $76 \%$ and $83 \%$ of the total SOC and STN variability, respectively, $12-40 \%$ higher than other models in the study area. Elevation had the largest influence on SOC and STN distribution. We conclude that the developed ISA model is robust and effective in mapping SOC and STN, particularly in the areas with complex 
vegetation-landscape when limited samples are available. The method needs to be tested for other regions in our future research. 
1 An improved similarity-based approach to predicting

2 and mapping soil organic carbon and soil total

3 nitrogen in a coastal region of northeastern China

Shuai Wang ${ }^{1,2,3}$, Kabindra Adhikari ${ }^{4}$, Qianlai Zhuang ${ }^{3}$, Zijiao Yang ${ }^{1}$, Xinxin Jin ${ }^{1 *}$, Qiubing Wang ${ }^{1}$, and Zhenxing Bian ${ }^{1}$

${ }^{1}$ College of Land and Environment, Shenyang Agricultural University, Shenyang, Liaoning

9 Province, China

${ }^{2}$ Key Laboratory of Ecosystem Network Observation and Modeling, Institute of Geographic Sciences and Natural Resources Research, Chinese Academy of Sciences, Beijing 100101, China

${ }^{3}$ Department of Earth, Atmospheric, and Planetary Sciences, Purdue University, West Lafayette, IN 47907, United States of America

${ }^{4}$ Grassland, Soil and Water Research Laboratory, USDA-ARS, Temple, TX 76502, United

States of America

Corresponding Author:

Xinxin $\operatorname{Jin}^{1}$

No. 120 Dongling Road, Shenhe District, Shenyang, Liaoning Province 110866, China

Tel: +86-24-8848-7155

Fax: +86-24-8848-7155

Email address: jinxinxin0218@163.com

\section{Abstract}

Soil organic carbon (SOC) and soil total nitrogen (STN) are major soil indicators for soil quality and fertility. Accurate mapping SOC and STN in soils would help both managed and natural soils and ecosystem management. This study developed an improved similarity-based approach (ISA) to predicting and mapping topsoil (0-20 cm soil depth) SOC and STN in a coastal region of northeastern China. Six environmental variables including elevation, slope gradient, topographic wetness index, the mean annual temperature, the mean annual temperature, and normalized difference vegetation index were used as predictors. Soil survey data in 2012 was designed based on the clustering of the study area into six climatic vegetation landscape units. In each landscape unit, 20-25 sampling points were determined at different landform positions considering local climate, soil type, elevation and other environmental factors, and finally 126 sampling points were obtained. Soil sampling from the depth of 0-20 cm were used for model prediction and validation. The ISA model performance was compared with the geographically weighted regression (GWR), regression kriging (RK), boosted regression trees (BRT) considering mean absolute prediction error (MAE), root mean square error (RMSE), coefficient of determination $\left(\mathrm{R}^{2}\right)$, and maximum relative difference $(\mathrm{RD})$ indices. We found that the ISA 
40

41

42

43

44

45

46

47

48

49

50

51

52

53

54

55

56

57

58

59

60

61

62

63

64

65

66

67

68

69

70

71

72

73

74

75

76

77

78

79

method performed best with the highest $\mathrm{R}^{2}$ and lowest MAE, RMSE compared to GWR, RK, and BRT methods. The ISA method could explain $76 \%$ and $83 \%$ of the total SOC and STN variability, respectively, $12-40 \%$ higher than other models in the study area. Elevation had the largest influence on SOC and STN distribution. We conclude that the developed ISA model is robust and effective in mapping SOC and STN, particularly in the areas with complex vegetation-landscape when limited samples are available. The method needs to be tested for other regions in our future research.

Keywords: Digital soil mapping, environmental variables, spatial variability, uncertainty

\section{Introduction}

Soil organic carbon (SOC) and soil total nitrogen (STN) influence soil physical, chemical, biological properties and processes and determine soil quality that is related to food security by affecting agricultural productivity (Batjes 1996; Wang et al. 2013; Elbasiouny et al. 2014). To a certain extent, SOC and STN affect the concentration of greenhouse gases in the atmosphere. The prediction of their sizes and changes has become a key climate change research area (Jobbagy \& Jackson 2000; Post \& Kwon 2000; Lal 2004; Davidson \& Janssens 2006; Yang et al. 2015). Previous studies indicated that the spatially explicit information of SOC and STN plays an important role in quantifying global carbon and nitrogen cycles (Kieft et al. 1998; Yang et al. 2015; Wang et al. 2017).

Numerous studies have been conducted to understand the relationships between SOC and STN with environmental factors including topography, climate and biology (e.g., Yang et al., 2016). To map the spatial variations of SOC and STN based on field observations, Digital soil mapping (DSM) technologies have proven as a rapid and inexpensive approach over large areas using a limited amount of sample data (McBratney et al., 2003; Yang et al., 2016). Commonly used DSM techniques include linear regression (Kunkel et al., 2011; Zhao et al., 2015), random forest (RF) (Grimm et al., 2008; Yang et al., 2016), regression kriging (RK) (Odeh et al., 1995; Zhao et al., 2015; Song et al., 2016), regression rules (Adhikari et al, 2014; Minasny and McBratney, 2008), boosted regression trees (BRT) (Yang et al., 2016; Wang et al., 2016), geographically weighted regression (GWR) (Kumar et al., 2012; Song et al., 2016), artificial neural networks (Burke et al., 1989; Were et al., 2015), similarity-based method (Zhu, 1997; Yang et al., 2015; Liu et al., 2016), and support vector machines (Kovačević et al., 2010; Stevens et al., 2010) .

DSM conceptually applies the soil-landscape model of Jenny (1941) which describes the changes in soil properties as a function of factors related to climate, organism, topography, parent material and time. Therefore, the soil and its environment are specifically and spatially related. Topography plays an important role in the process of soil development and formation. Its impact on soil formation is mainly through the redistribution of water, nutrients, and energy, affecting microclimate and biomes, thus indirectly influencing the spatial distribution of SOC, and STN (Adhikari et al., 2018; Mondal et al., 2017; Garten Jr and Ashwood, 2002; Moore et al., 
80

81

82

83

84

85

86

87

88

89

90

91

92

93

94

95

96

97

98

99

100

101

102

103

104

105

106

107

108

109

110

111

112

113

114

115

116

117

118

119

1993). In the central highlands of Ethiopia, Tesfaye et al (2016) found topography as the main factor affecting the spatial variation of SOC and STN content in the region. Similarly, climatic influences on soil formation and development are mainly through temperature, and precipitation and their interactive effects. Jobbagy and Jackson (2000) applied three global-scale soil profile datasets to estimate the global SOC stocks in 3-m deep soil layer, and pointed out that temperature and precipitation were the main climatic factors affecting the changes in SOC stocks. Hudson (1992) considered that soil-forming factors in a landscape interact with each other in a particular manner, indicating that the same soil-landscape presents with homogeneous soil types. According to this theory, the relationship between soil and soil-forming factors can be used to infer the spatial distribution of soil properties. Similarly, Zhu et al. (1997) suggested that soilforming factors indicate the spatial distribution of soil properties. Thus, similar soilenvironmental conditions can be assumed to exhibit similar soil types and properties. Based on this hypothesis, the complex environment can be divided into several less heterogeneous landscape units with potentially similar soil-forming environment. Soil properties in these landscape units can be further represented by the characteristics of the sample points within the landscape. The similarity-based method (Zhu 1997) has been applied and proven to be an efficient method in predictive soil mapping. It has been widely used in the prediction of soil properties and soil types (Liu et al. 2016; Liu 2010; Zhu et al., 2010). Yang et al. (2015) used the similarity-based approach to map the spatial variation of soil salinity and obtained a higher prediction accuracy. A higher performance of similarity-based mapping approach was also confirmed by Shi et al. (2004), who generated a soil series map with $86 \%$ prediction accuracy. Liu et al. (2010) indicated that the similarity-based approach exhibited notable predictive performance compared to a kriging interpolation method applied in Ili of Xinjiang, China. Similarly, Liu et al. (2016) integrated a similarity-based approach with depth functions to model the three-dimensional (3D) distribution of SOM and obtained a lower global mean error $(0.06 \mathrm{~g}$ $\mathrm{kg}^{-1}$ ). Their findings showed that the similarity-based approach combined with other models can accurately predict soil properties.

The spatial distribution of SOC and STN in a landscape can be influenced by topography, organic matter input, temperature, humidity, vegetation, parent material and soil management (Sollins et al., 1996; Camino-Serrano et al., 2014), and can be better estimated by dividing the landscape into sub-units. To achieve this, some previous studies used data segmentation techniques to establish the relationship between SOC and STN with specific environmental variables for smaller regions. For instance, Mulder et al. (2015) divided France into 10 soillandscape types using a model-based clustering technology based on climate, vegetation, geology, and soil environmental variables and the regression models between SOC and environmental variables were established for each landscape. They found that the classification and prediction at each soil-landscape unit could better explain the SOC variations.

This study improved a similarity-based approach (ISA) to predict and map the spatial distribution of SOC and STN by applying soil property data and environmental variables. In the ISA model, the whole study area is clustered into several typical climatic-vegetation landscape 
120

121

122

123

124

125

126

127

128

129

130

131

132

133

134

135

136

137

138

139

140

141

142

143

144

145

146

147

148

149

150

151

152

153

154

155

156

157

158

159

units by using gaussian mixture model for model-based clustering (GMMC). The spatial prediction of SOC and STN was then carried out by using the similarity-based approach in this region. In the GMMC model, the expectation maximization algorithm is adopted to estimate the model parameters, whereas the Bayesian Information Criterion (BIC) is used to optimize the clustering results, the optimal model and the numbers of clusters are then selected. This study attempts to test the ISA model by comparing it with the commonly used DSM methods such as geographically weighted regression, regression kriging and boosted regression trees models. The proposed ISA model was tested to map SOC and STN in Montane ecosystems of Lushun City in the northeastern coastal areas of China. Our research objectives to: (1) developed a GMMC method to divide the study area into climate-vegetation landscape units; (2) model the effect of environmental variables on SOC and STN variation; and (3) map the SOC and STN distribution using ISA, GWR, RK, and BRT models and compared their performances.

\section{Materials \& Methods}

\section{Study area}

The study area $\left(38.72^{\circ}-38.97^{\circ} \mathrm{N}, 121.08^{\circ}-121.47^{\circ} \mathrm{E}\right)$ covers approximately $512 \mathrm{~km}^{2}$ and is located in Lushun City, Liaoning Province in the northeast coast of China (Figure 1). The area lies in the southwest corner of Liaodong Peninsula and faces towards the Yellow Sea on the east and Bohai Sea on the west. Therefore, this region presents typical continental and oceanic climate characteristics forming unique climate-vegetation landscapes including coastal plain, interior plain, medium-coverage grasslands, high-coverage grasslands, low-elevation forest, and low-mountain shrub. The area is dominated by mountain landscape, which accounts for $53.1 \%$ of the total area and is characterized by valleys and peaks, with an altitude ranging from 137 to 466 $\mathrm{m}$ above sea level. The mean annual temperature (MAT) in this region is nearly $10{ }^{\circ} \mathrm{C}$, the maximum and minimum temperatures are $27.5^{\circ} \mathrm{C}$ in September and $8.2^{\circ} \mathrm{C}$ in January. The region experiences a total of 185 frost-free days with the mean annual precipitation (MAP) ranging from $585 \mathrm{~mm}$ to $720 \mathrm{~mm}, 65-75 \%$ of which falls between June and September. According to World Reference Base for Soil Resources (WRB), the dominant soil types are Cambisols and Fluvisols (Schad et al. 2014).

(Figure 1 is about here)

\section{Dataset}

\section{Field sample data}

Almost 53\% of the study area is under forests, and is densely covered with rivers and valleys where the river system is rather complicated in a rugged terrain. To represent the spatial characteristics of soil properties in such a complex landscape, we applied a stratified sampling scheme following two steps.

First, we used a GMCC method to divide the study area into several typical climaticvegetation landscape units. The GMMC model is a hybrid model composed of the gaussian mixture model (GMM) and the expectation maximization (EM) algorithm. The GMM model is 
160

161

162

163

164

165

166

167

168

169

170

171

172

173

174

175

176

177

178

179

180

181

182

183

184

185

186

187

188

189

190

191

192

193

194

195

196

197

198

199

200

used to determine certain probability density functions (i.e., the probability of data points is partitioned into each category) (Banfield et al., 1993) to achieve the division of datasets. The EM algorithm is adopted to estimate the model parameters, whereas the BIC is used to optimize the clustering results, and then the optimal model and the number of clusters are selected. The clustering model is established in the R version 3.2.2 (R Development Core Team, 2013) using the "mclust" package (Fraley \& Raftery, 2002) for completion. Based on the pedogenetic information of the study area, environmental factors such as elevation, MAT, MAP, and normalized difference vegetation index (NDVI) were used as inputs (Zhu et al., 2008; Yang et al. 2013; Yang et al. 2016). The study area was divided into six climate-vegetation landscape units (Figure 2). Within each climate-vegetation landscape, twenty to twenty-five sampling points were identified at different landform positions considering local climate, soil type, elevation and other environmental factors.

Although soil sampling in this study considered climate and vegetation properties of the landscape for clustering, it was further verified by the local soil experts to determine whether the units are typical and are representative of the study area. This data sampling was not based on probability sampling strategy, thus it might underestimate or overestimate the SOC and STN distribution in the region as reported in previous studies (Zhu, 1997; Yang L et al., 2016). However, it was probably the best sampling option given that sampling was done in such a densely forested terrain and with limited resources. Overall flowchart of the proposed methodology is shown in Figure 3.

(Figure 2 is about here)

(Figure 3 is about here)

A total of 126 sample locations were established, and the geographic coordinates of each point was recorded by a handheld global positioning system (GPS) (Table S1). From each sample location, about $1 \mathrm{~kg}$ of topsoil (0-20 cm soil depth) sample was collected for laboratory analysis. In the Testing \& Analysis Center of Shenyang agricultural University, Shenyang, Liaoning Provence, China, the litters were removed from samples. The samples were then air dried, grinded, and passed through a 2-mm sieve. SOC and STN contents were measured by a dry combustion method (Matejovic, 1993) using CN analyzer (Vario Max, Elementar Amerivas Ins., Germany). The soil depth considered in this study was limited to $0-20 \mathrm{~cm}$ because Wang et al. (2017) found that in Liaoning Province, 69\% of SOC and STN were stored in the topsoil (0$30 \mathrm{~cm})$. It has been further confirmed by Liu et al. (2012) who reported about $43 \%$ of the SOC stocks from the topsoil. In addition, $70 \%$ of all samples were randomly selected as training dataset $(n=88)$ and the rest $30 \%$ as independent verification dataset $(n=38)$.

\section{Environmental variables}

Two topographic variables including slope gradient and topographic wetness index (TWI) were used in addition to four other variables (elevation, MAP, MAT, and NDVI) for climatevegetation landscape partition (Table 1), to predict the spatial distribution of SOC and STN content. The variables were collected from different sources and were converted to a raster grid

PeerJ reviewing PDF | (2019:11:43319:2:0:NEW 11 Apr 2020) 
201

202

203

204

205

206

207

208

209

210

211

212

213

214

215

216

217

218

219

220

221

222

223

224

225

226

227

228

229

230

231

232

233

of $30 \mathrm{~m}$ resolution. Measured data on SOC and STN, and all the predictors were brought into the geographic information system (GIS) in a common projection system (Krasovsky_1940_Albers) in ArcGIS 10.2 (ESRI Inc., USA) for further geospatial processing and analysis. Slope gradient and TWI were derived from a 30-m resolution digital elevation model (DEM) captured from Shuttle Radar Topography Mission (SRTM) (Farr and Kobrick, 2000). MAT and MAP as two main climatic variables obtained from China Meteorological Data Service Center (http://data.cma.cn/en) as 30-year annual average (1980-2010). In addition, we selected NDVI to represent vegetation intensity, as determined by using two bands of Landsat 5, namely, band 3 and band 4 (Equation 1), and were downloaded from the United States Geological Survey (USGS). The imagery covers from July to September of 2012 with $<10 \%$ cloud cover. Image processing included geometric correction, registration, image mosaic and clipping, cloud removal, and shadow processing and was performed in ENVI 4.7 software (Huang et al., 2007).

$$
N D V I=\frac{(\text { band } 4-\text { band } 3)}{(\text { band } 4+\text { band } 3)}
$$

\section{Model development}

\section{Improved similarity-based approach and its prediction consistency}

An improved similarity-based approach was used to estimate the soil properties of unsampled location by acquiring the environmental similarity with sampling points. Specifically, this method was developed following three key steps:

Step 1 was to calculated the environmental similarity in each climate-vegetation landscape;

$D=\sqrt{\left(S_{1}-U_{1}\right)^{2}+\left(S_{2}-U_{2}\right)^{2}+\ldots+\left(S_{i}-U_{i}\right)^{2}}$

In this equation, $D$ is Euclidean distance; $S i$ and $U i$ are sampled point $S$ and unsampled point $U$, respectively, and the variable values in dimension $i$ space. Suppose there are $m$ sampling points and $n$ unsampled points, then a set of Euclidean distance $(D E)$ matrix can be obtained as:

$$
D E=\left[\begin{array}{cccc}
D_{11}, & D_{21}, & \ldots, & D_{n 1} \\
D_{12}, & D_{22} & \ldots, & D_{n 2} \\
\ldots & & & \\
D_{1 m} & D_{2 m} & \ldots, & D_{n m}
\end{array}\right]
$$

Euclidean distance only measures the degree of distance between two points. In order to obtain the similarity between two points, it must be converted into the corresponding similarity. We first applied equation (4) to obtain standard range of Euclidean distance $\left(D E_{\text {scale }}\right)[0,1]$, and then applied equation (5) to convert it into similarity $(S E)$ with range $[0,1]$

$$
\begin{aligned}
& D E_{\text {scale }}=D E / \max (D E) \\
& S E=1-D E_{\text {scale }}
\end{aligned}
$$


234

235

236

237

238

239

240

241

242

243

244

245

246

247

248

249

250

251

252

253

254

255

256

257

258

259

260

261

262

263

264

265

266

267

268

269

So, the similarity matrix $(S E)$ between the unsampled locations and the sampling points was obtained using equation (6):

$$
S E=\left[\begin{array}{cccc}
S_{11}, & S_{21}, & \ldots, & S_{n 1} \\
S_{12,} & S_{22} & \ldots, & S_{n 2} \\
\ldots & & & \\
S_{1 m} & S_{2 m} & \ldots, & S_{n m}
\end{array}\right]
$$

Step 2 was to predict soil properties for the landscape unit according to its environmental similarity.

In each landscape, the soil property value of the unsampled locations was predicted by using the environmental similarity where elevation, MAT, MAP, NDVI, TWI, and slope gradient were used as predictors. The definite equation as follows:

$V_{b}=\sum_{a=1}^{m} S_{a b} \cdot V_{a} / \sum_{a=1}^{m} S_{a b}$

where $V_{b}$ is the predicted value of soil property at location $b$ and $V_{a}$ is the soil property value at sampled location $a ; S_{a b}$ is the environmental similarity between location $b$ and sampled location $a ; m$ is the number of sampling points.

Step 3 was to calculate the prediction consistency using Equation (8):

Consistency $_{m}=1-\max \left(S_{1 m}, S_{2 m}, \ldots, S_{n m}\right)$

where Consistency $y_{m}$ is the prediction consistency at point $m$, and the lower the value, the better the prediction consistency of the model; $S_{n m}$ is the environmental similarity between point $n$ and sampled location $m$.

According to equation (8), the maximum value can be used to obtain the best representation of the similarity of the environment between unsampled locations and sampling points (i.e., most similar). With a low similarity, the sampling points cannot represent the unsampled locations (Liu 2010) and the soil property values inferred from the sampling points will show a high degree of speculative consistency.

\section{Geographically weighted regression}

Geographically weighted regression was first introduced into the study of geography by Brunsdon et al. (1998). It embeds the spatial structure of the data into a regression model making the regression parameters become a function of the geographical location of the observation points. GWR is a non-parametric technique based on local weighted regression developed for curve fitting and smoothing applications in statistics (Kumar et al., 2012). In this technique, local regression parameters are estimated using a subset of data close to the estimated points of models in variable spaces. The innovation of GWR is to use a subset of data in geographic space near the calibration location of the model. In our GWR model, six environmental variables were used to predict the spatial distribution of SOC and STN.

\section{Regression kriging}

Regression kriging is a spatial interpolation technique that combines a regression of the dependent variable and auxiliary variables (such as terrain parameters, remote sensing imagery and thematic maps) with kriging of the regression residuals (Odeh et al. 1995; Hengl et al. 2004). 
270 We applied RK to interpolate the spatial distribution of SOC and STN following these five 271 steps: (1) determining the SOC and STN prediction model using multiple linear regressions 272 (MLR); (2) calculating the SOC and STN prediction model residuals at each calibration location; 273 (3) modeling the covariance structure of the SOC and STN residuals using a variogram GS+7.0 274 statistical software (Gamma Design Software, Plainwell, MI) was used to implement this 275 process; (4) spatially interpolating the SOC and STN residuals through the parameters of the 276 variogram model; and (5) adding the SOC and STN prediction model surface to the interpolated 277 residuals surface to get the final predicted map.

\section{Boosted regression trees}

279 Boosted regression trees model is a machine learning algorithm based on classification and 280 regression trees, which was proposed by Friedman (2000). The BRT model is similar to other 281 boosting models improving model performance by training multiple models and combining them 282 for prediction. It consists of two algorithms: regression trees and gradient boosting. In the model, 283 gradient lifting algorithm is used to linearly combine multiple regression trees of weak

284

285

286

287

288

289

290

291

292

293

294

295

296

297

298

299

300

301

302

303

304 regression to form an efficient and a strong regression model (e.g., Wang et al, 2016; Yang et al, 2016). The implementation of BRT model requires users to define four parameters: learning rate (LR), tree complexity (TC), bag fraction (BF) and tree number (NT). LR represents the contribution of each tree in the model to the final fitting model (Yang et al., 2016). TC is a direct predictor of tree depth and maximum interaction level (Yang et al., 2015). BF represents the scale of data used in each model (Wang et al., 2018). NT is determined by LR and TC. In order to obtain the best prediction performance of BRT model, different parameter combinations LR $(0.0025,0.025,0.25,0.50)$, TC $(3,6,9)$, BF $(0.20,0.35,0.50,0.65)$, NT $(600,800,1000,1200)$ were tested by 10 -fold cross-validation. Finally, LR, TC, BF and NT values that achieved the minimum prediction error through 10 -fold cross-validation were set to $0.0025,6,0.65$, and 800 , respectively, for SOC prediction, and $0.025,6,0.65$ and 1000, respectively, for STN prediction.

\section{Model Validation}

In each landscape, $30 \%$ sampling points (38 observations in total) were randomly selected to test the prediction performance of the ISA, GWR, RK, and BRT methods. Three commonly-used indices including mean absolute prediction error (MAE), root mean square error (RMSE), coefficient of determination $\left(\mathrm{R}^{2}\right)$, and maximum relative difference (RD) (Equation 9 to 11) were used to compare the model. All indices were calculated in the $\mathrm{R}$ version 3.2.2 ( $\mathrm{R}$ Development Core Team, 2013):

$M A E=\frac{1}{n} \sum_{i=1}^{n}\left|a_{i}-b_{i}\right|$

RMSE $=\sqrt{\frac{1}{n} \sum_{i=1}^{n}\left(a_{i}-b_{i}\right)^{2}}$

$$
R^{2}=\frac{\sum_{i=1}^{n}\left(a_{i}-\bar{b}_{i}\right)^{2}}{\sum_{i=1}^{n}\left(b_{i}-b_{i}\right)^{2}}
$$


305

306

307

308

309

310

311

312

313

314

315

316

317

318

319

320

321

322

323

324

325

326

327

328

329

330

331

332

333

334

335

336

337

338

339

340

341

342

343

$$
R D=\frac{\bar{a}_{i}-\bar{b}_{i}}{\bar{a}_{i}}
$$

where $a_{i}, b_{i},{ }{ }_{i}$, and $\bar{b}_{i}$ are the observed values, predicted values, and mean values of soil property at site $i$, and $n$ is the number of the sampling point.

\section{Results}

\section{Exploratory Data Analysis}

Exploratory analysis of measured SOC and STN contents and values of environmental variables at sampling locations are summarized in Table 1. Average SOC and STN in the topsoil were ( \pm 3.78), and $0.85( \pm 0.23) \mathrm{g} \mathrm{kg}^{-1}$, respectively. The skewness and kurtosis coefficients were 1.07 and 0.06 for SOC and 0.81 and -0.31 for STN, respectively, indicating that the measured SOC and STN approximately followed a normal distribution. In addition, both distribution passed Kolmogorov-Smirnov (K-S) test $(\rho=0.11$ and 0.09$)$, respectively, suggesting that SOC and STN data did not need to be transformed for subsequent analysis and modeling.

(Table 1 is about here)

SOC and STN were positively correlated with NDVI, MAP, elevation, and slope gradient but negatively correlated with MAT and TWI (Figure 4). We observed multicollinearity among environmental variables and believed that predicting SOC and STN with these variables using traditional statistical methods such as simple multiple regression equations would be unreliable (McBratney et al. 2003; Yang et al. 2016) and using ISA model could effectively overcome this problem. In the process of GWR modeling, we eliminated the slope gradient variable as it was highly correlated with MAT and elevation, to avoid the problem of multicollinearity, and used the remaining five variables for spatial prediction.

\section{Climate-vegetation landscape}

(Figure 4 is about here)

SOC and STN usually vary in the long term and are influenced by various environmental factors (i.e., rainfall, temperature, and vegetation). As a typical coastal ecosystem in Northeast China, Lushun has both continental and marine climate characteristics with an absence of cold winter and hot summer. Therefore, we selected the elevation, MAT, MAP, and NDVI to divide the region into the climate-vegetation landscape units. The results showed that the study area can be divided into six climate-vegetation landscapes (BIC, -678247.3) (Figure 2). Landscapes 1, 2 are mainly distributed in the northern and western region of the study area; Landscapes 3 and 4 are mainly for the central region; and Landscapes 5, 6 are mainly distributed in the northeastern and southern regions. In terms of the area distribution area of landscapes, landscape 5 accounting for $25 \%$ of the total area of the study area, followed by landscape $3(21 \%)$, landscape $2(18 \%)$, landscape 4 (18\%), landscape 1 (12\%), and landscape 6 (6\%) (Figure 2).

The distribution of climate-vegetation landscapes and soil observations by elevation, MAP, MAT, and NDVI is shown in Figure 5. The statistical characteristics of the four environmental 
344

345

346

347

348

349

350

351

352

353

354

355

356

357

358

359

360

361

362

363

364

365

366

367

368

369

370

371

372

373

374

375

376

377

378

379

380

381

382

383

variables at sampling points were similar to those in the landscapes, indicating that the sampling points could efficiently describe the characteristics of the major environmental factors in the study area. However, some differences in the main environmental variables of each landscape were observed. The Landscape 1 showed the lowest average elevation, a low MAP $(608 \mathrm{~mm})$, and the highest MAT $\left(10.6^{\circ} \mathrm{C}\right)$, and the average NDVI value approached 0.4 . Therefore, the landscape type was coastal plain. Compared with landscape 1, landscape 2 was distributed at a relatively low elevation but presented a better vegetation cover; therefore, the landscape type was named interior plain. Landscape 6 showed the highest elevation $(210 \mathrm{~m})$, lowest MAT $\left(10.0^{\circ} \mathrm{C}\right)$, and lowest value of NDVI; thus, the landscape type was low-mountain shrub. Landscapes 3, 4, and 5 were mainly distributed in the middle elevation, but their MAT and NDVI values were different. Landscapes 3 and 4 showed higher precipitation rates; however, given the limitation of temperature, low vegetation cover was observed, thus landscapes 3 and 4 were classified as medium-coverage grasslands and high-coverage grasslands. Landscape 5 presented a better vegetation cover, and was classified as low-elevation forest.

(Figure 5 is about here)

\section{Model Performance}

In order to determine whether the study area should be divided into unique landscape units, and then use the best prediction model to predict the spatial distribution of SOC and STN in each landscape, the MAE, RMSE, and $\mathrm{R}^{2}$ were compared between the observed and predicted values (Table 2). The results showed that the model was significantly improved by dividing the study area into climate-vegetation landscapes (Table 2).

(Table 2 is about here)

To obtain the best prediction model, four models (ISA, GWR, RK, and BRT) were compared using 38 independent validation points. Results showed that the ISA model outperformed GWR, RK, and BRT models with a lower MAE and RMSE, and a higher $\mathrm{R}^{2}$ values. We also found that the performance of BRT was better than the GWR and RK models. ISA model was efficient and powerful in spatial prediction of SOC, and STN among six climatic vegetation landscape units based on the accuracy verification. The prediction accuracy of ISA model in each landscape is listed in Table 3. The mean predicted values of SOC and STN in the topsoil were comparable to the mean observed values of the sampling points (Table 3). $\mathrm{RD}$ was obtained in the interior plain (RD about $7.1 \%$ and $4.2 \%$ ), followed by the coastal plain (RD about $3.4 \%$ and $3.3 \%$ ) and lowmountain shrub ( $\mathrm{RD}$ about $-4.2 \%$ and $-4.1 \%$ ), and the $\mathrm{RD}$ values of the other landscapes were smaller (Table 3). The predicted $\mathrm{R}^{2}$ ranged from 0.37 (Low-mountain shrub) to 0.77 (Interior plain) for SOC and 0.39 (Low-mountain shrub) to 0.89 (Median-coverage grassland) for STN, respectively. The lowest RMSE $\left(0.13 \mathrm{~g} \mathrm{~kg}^{-1}\right)$ in SOC prediction was reported for Mediumcoverage grassland and the highest $\left(2.53 \mathrm{~g} \mathrm{~kg}^{-1}\right)$ for Low-elevation forest. For the STN, RMSE 
384

385

386

387

388

389

390

391

392

393

394

395

396

397

398

399

400

401

402

403

404

405

406

407

408

409

410

411

412

413

\section{Discussion}

415

416

417

418

419

420

421

422

423 predictability.

ranged from 0.01 to 0.06 depending on the landscape types. Overall, the lower MAE and RMSE, and higher $\mathrm{R}^{2}$ value for ISA model compared to the rest of the models indicated that the ISA model could better predict SOC and STN distribution.

(Table 3 is about here)

For SOC prediction using the ISA model, MAE, RMSE, and $\mathrm{R}^{2}$ values were $0.74,1.01 \mathrm{~g} \mathrm{~kg}^{-}$ 1 , and 0.76 , respectively, and for STN, the values were $0.03,0.04 \mathrm{~g} \mathrm{~kg}^{-1}$, and 0.83 , respectively (Figure 6). The ISA model overestimated the SOC and STN contents in the study area, but the overall accuracy was high. The model explained approximately $76 \%$ and $83 \%$ of the total SOC and STN variability in the study area, respectively. Predictive consistency maps of SOC and STN were obtained using Equation 8. The higher the consistency value, the larger the difference between the predicted value and measured value. Mean prediction consistency values were 0.14 for SOC and 0.13 for STN, respectively (Figure 7a, 7b), suggesting the ISA model had a reliable

\section{Estimates of SOC and STN}

SOC and STN distribution was mapped using the ISA model where an average SOC and STN content in the study area was $11.37( \pm 3)$ and $0.89( \pm 0.2) \mathrm{g} \mathrm{kg}^{-1}$, respectively (Figure 7c, 7d). In terms of spatial pattern, ISA model was more excellent than other models (Figure S1). Among the climate-vegetation landscape units, soils under low-elevation forests contained more SOC and STN than the rest of the landscape units (Table 4). Of all predictors, elevation was the main predictor affecting the spatial distribution of SOC and STN in the study area (Figure 8).

(Table 4 is about here)

(Figure 8 is about here)

\section{Effects of ISA model on SOC and STN}

The study area divided into unique landscape units, and then used the best prediction model to predict the spatial distribution of SOC and STN in each landscape. The results showed that the model was significantly improved by dividing the study area into climate-vegetation landscapes. This is consistent with previous studies using the same method. For instance, in Belgium, Lettens et al. (2004) divided the whole study area into 289 landscape units and predicted the SOC stocks for each landscape unit. They considered that SOC stocks were continuously influenced by a number of external factors, mainly land-use history and current land management and climate. The spatial distribution of SOC and STN varies closely with climate-vegetation-dominated 
424 landscapes. By dividing a large-scale complex landscape into small units, the SOC and STN 425 could be better predicted. At the same time, compared to other SOC and STN prediction studies 426 in the coastal area, the ISA model we constructed performed better. For example, in Santa Cruz 427 Island, Galapagos, Rial et al. (2017) used terrain, climate and remote sensing variables combined with a GWR method to predict topsoil SOC stocks, and their model could explain $66 \%$ of SOC

430

431

432

433

434

435

436

437

438

439

440

441

442

443

444

445

446

447

448

449

450

451

452

453

454

455

456

457

458

459

460

461

462

463 stocks variation in the region. In a separate study, Wang et al. (2018b) compared GWR and RK models to predict topsoil SOC in the Northeast coastal area of China and found GWR a better model that could explain 78\% and 80\% SOC variation during 1982 and 2012, respectively.

The ISA model could explain approximately $76 \%$ and $83 \%$ of the total SOC and STN variability in the study area, respectively. In comparison with previous studies, we observed a better prediction performance of the ISA method. Yang et al. (2016) developed a BRT model that explained 50 to $58 \%$ of the SOC variability in the Qinghai Tibet Plateau, China. Using a GWR approach, Wang et al. (2013) captured approximately $57 \%$ of the STN variability in Fujian Province, China. In the Medinipur Block, Paschim Medinipur District and West Bengal in India, Bhunia et al. (2019) used remote sensing techniques and multivariate regression model, which explained $71 \%$ of SOC variability. Xu et al. (2018) used six different remote sensing spectral indices of RK models to predict STN in two smallholder villages, Kothapally and Masuti in South India, which helps explain 59\% of the STN variability in the region.

Overall, the ISA model prediction consistency was higher towards the eastern part of the study area compared to the rest area for both SOC and STN predictions. Although there were other sources of uncertainty and error in mapping SOC and STN, including sampling error, laboratory analysis errors, and low predictor precision (Wang et al. 2017; McBratney et al. 2003; Yang et al. 2016; Grimm et al. 2008), quantification of these inevitable errors were not considered in this study.

\section{Predicted distribution of SOC and STN content}

In general, the spatial distribution pattern for SOC and STN was similar and varies with different climate-vegetation landscape units (Figure 3, 5, and 7). Spatially, higher SOC and STN were in the northeastern and southern regions that were dominated by low-elevation forest and lowmountain shrub. Coastal plain has the lowest SOC and STN. Overall, the lowest SOC and STN contents were found in the northern and central regions with low MAT and vegetation coverage. These results are consistent with the findings of Jobbagy \& Jackson (2000) and Ding et al. (2018) who reported for humid and rainy areas. Soil particles in high-elevation areas were easy to lose and thick soil layers were formed in low-elevation areas, which were conducive to the accumulation of SOC and STN. Of the six climate-vegetation landscape units, soil under coastal plain had the lowest SOC and STN as also reported in Causarano et al. (2008). The low SOC and STN in these landscape units might be caused by increased organic matter decomposition and erosion and tillage losses (Burke et al., 1989; Lettens et al., 2004; Adhikari and Hartemink, 2015).

We observed that with increasing elevation, this is true for forest pixels (Figure 8). The effect of elevation on SOC and STN has been examined in a number of studies (e.g., Kieft 1998; 
464 Kunkel et al. 2011; Minasny et al., 2013; Adhikari et al. 2013; Chen et al. 2015; Minasny et al., 465 2017; Liang et al., 2019). Wang et al. (2017) reported that SOC and STN significantly increased 466 with elevation. Differences in elevation gradients may have affected the input and loss of soil 467 carbon and nitrogen mainly through indirect factors along the gradient, such as precipitation and 468 temperature (Minasny et al., 2013; Elbasiouny et al. 2014; Were et al. 2015; Adhikari \& Hartemink 2015).

The predicted distribution of SOC and STN showed a discontinuous pattern (Figure $7 \mathrm{c}$ and 7d). We found that the abrupt change in SOC and STN contents were located at the junction of landscapes. Such a pattern was due to the method of landscape division leading to an abrupt change of different landscape boundaries (Jaeger 2000; Peilin et al. 2010). The apparent partitioning between landscapes led to spatially discontinuous distribution of SOC and STN, resulting in may lead to certain unreasonable predictions (Rosenbloom et al. 2006). This pattern may be attributed to the evident transition between the two landscapes, but the transition zone was smaller than the pixel resolution (Belshe et al. 2012).

Although the ISA model constructed in this study had a good performance in predicting SOC and STN content, there were still some limitations. Firstly, we used a soil-landscape model to collect soil samples, which is idiosyncratically suitable for the ISA model. An independent probability sampling method would be required in our subsequent research. Secondly, this study

484

485

486

487

488

489

490

491

492

493

494

495

496

497

498

499

500

501

502

503 area was divided into several typical climate-vegetation landscape units and then applied the model to simulate their SOC and STN. This treatment ignored the gradual transition between landscape units with respect to SOC and STN, which might have biased our regional prediction. In the future, the model should be revised to avoid this bias. Thirdly, because the study area was dominated by mountains, which were easily affected by the terrain and clouds, the high-altitude areas were prone to produce shadows in the process of image segmentation, resulting in large reflectivity errors of satellite image data. This might have also introduced prediction errors. Finally, this research was limited to topsoil $(0-20 \mathrm{~cm})$ SOC and STN content, which might have led to underestimating SOC and STN due to a large amount of SOC and STN typically stored in deeper soil layers in the region.

\section{Conclusions}

This study advanced an ISA model to predict the spatial distribution of SOC and STN in the Northeast coastal area of China. The ISA model incorporated a GMMC method to divide the study area into six climatic-vegetation landscapes first. The six landscapes were then modeled using a t theory of environmental similarity. Comparing the prediction of GWR, RK, and BRT models, we found that the ISA model was the most robust and effective method in mapping SOC and STN, which explained $78 \%$ and $83 \%$ of the spatial variation of SOC and STN in the study area, respectively. Of the six climate-vegetation landscape units, the soils under low-elevation forest had the highest level of SOC and STN content than soils under the rest of the landscape units including coastal plain, interior plain, medium-coverage grasslands, low-mountain shrub, and high-coverage grasslands. Topography is the main driving force of SOC and STN 
504 distribution in the Northeast coastal area. Therefore, we suggested that terrain variables should

505 be included in future SOC and TN mapping studies, especially in coastal and hilly areas of China.

506 Overall, the improved ISA method better predicted SOC and STN in the region. Our predicted

507 SOC and STN distribution shall provide important information for soil and water conservation,

508 ecological restoration, environmental management and agricultural production planning in the

509 Northeast coastal agricultural region.

510

511

Acknowledgements

512

513

\section{References}

514 Adhikari K, Hartemink AE. 2015. Digital mapping of topsoil carbon content and changes in

515 the Driftless Area of Wisconsin, USA. Soil Science Society of America Journal 79(1):155-164.

516

Adhikari K, Hartemink AE, Minasny B, Kheir RB, Greve MB, Greve MH. 2014. Digital

517

518 mapping of soil organic carbon contents and stocks in Denmark. PloS one 9(8): e105519.

519

520

521

522

523

524

525

526

527

528

529

530

531

532

533

Adhikari K, Kheir RB, Greve MB, Greve MH. 2013. Comparing kriging and regression approaches for mapping soil clay content in a diverse Danish landscape. Soil Science 178(9): 505-517.

Adhikari K, Owens PR, Ashworth AJ, Sauer TJ, Libohova Z, Richter JL, Miller DM. 2018. Topographic controls on soil nutrient variations in a silvopasture system. Agrosystems, Geosciences \& Environment 1(1):1-15.

An YM, Yang L, Zhu AX, Qin CZ, Shi JJ. 2018. Identification of representative samples from existing samples for digital soil mapping. Geoderma 311:109-119.

Banfield JD, Banfield AE. 1993. Model-based Gaussian and non-Gaussian clustering. Biometrics 803-821.

Batjes NH. 1996. Total carbon and nitrogen in the soils of the world. European journal of soil science 47:151-163.

Belshe EF, Schuur EAG, Bolker BM, Bracho R. 2012. Incorporating spatial heterogeneity created by permafrost thaw into a landscape carbon estimate. Journal of Geophysical Research: Biogeosciences 117: (G1).

534

535

536

537

538

Bhunia GS, Kumar Shi P, Pourghasemi HR. 2019. Soil organic carbon mapping using remote sensing techniques and multivariate regression model. Geocarto International 34(2): 215-226.

Brunsdon C, Fotheringham S, Chariton M. 1998. Geographically weighted regressionmodeling spatial non-stationarity. The Statistician 47:431-443.

Burke IC, Yonker CM, Parton WJ, Cole CV, Schimel DS, Flach K. 1989. Texture, climate, 539 Society of America Journal 53(3):800-805.

540 Causarano, HJ, Franzluebbers AJ, Shaw JN, Reeves DW, Raper RL, Wood C. 2008. Soil 541 organic carbon fractions and aggregation in the Southern Piedmont and Coastal Plain. Soil

542 Science Society of America Journal 72(1): 221-230. 
543 Chen C, Hu K, Li H, Yun A, Li B. 2015. Three-dimensional mapping of soil organic carbon by

544

545

546

547

548

549

550

551

552

553

554

555

556

557

558

559

560

561

562

563

564

565

566

567

568

569

570

571

572

573

574

575

576

577

578

579

580

581

combining kriging method with profile depth function. PloS one 10(6):e0129038.

Clement F, Orange D, Williams M, Mulley C, Epprecht M. 2009. Drivers of afforestation in Northern Vietnam: assessing local variations using geographically weighted regression. Applied Geography 29: 561-576.

Conrad O., Bechtel B., Bock M., Dietrich H., Fischer E., Gerlitz L., Wehberg J., Wichmann V., Böhner J., 2015. System for automated geoscientific analyses (SAGA) v. 2.1.4. Geoscientific Model Development 8 (7), 1991-2007.

Danielsson PE. 1980. Euclidean distance mapping. Computer Graphics and image processing 14(3):227-248.

Davidson EA, Janssens IA. 2006. Temperature sensitivity of soil carbon decomposition and feedbacks to climate change. Nature 440:165-173

Dempster AP, Laird NM, Rubin DB. 1977. Maximum Likelihood from Incomplete Data Via Em Algorithm. Journal of the Royal Statistical Society 39:1-38.

Ding J., Yang A., Wang J., Sagan V., Yu D. 2018. Machine-learning-based quantitative estimation of soil organic carbon content by VIS/NIR spectroscopy. PeerJ 6, e5714.

Elbasiouny H, Abowaly M, Abu_Alkheir A, Gad A. 2014. Spatial variation of soil carbon and nitrogen pools by using ordinary Kriging method in an area of north Nile Delta, Egypt. Catena 113: 70-78.

Farr TG, Kobrick M. 2000. Shuttle Radar Topography Mission produces a wealth of data. Eos, Transactions American Geophysical Union 81(48): 583-585.

Fraley C, Raftery AE. 2002. Model-based clustering, discriminant analysis, and density estimation. Journal of the American statistical Association 97:611-631

Friedman J, Hastie T, Tibshirani R. 2000. Additive logistic regression: a statistical view of boosting. The Annals of Statistics 28(2):337-407.

Fuchs H, Magdon P, Kleinn C, Flessa H. 2009. Estimating aboveground carbon in a catchment of the Siberian forest tundra: Combining satellite imagery and field inventory. Remote Sensing of Environment 113(3):518-531.

Garten Jr CT, Ashwood TL. 2002. Landscape level differences in soil carbon and nitrogen: implications for soil carbon sequestration. Global Biogeochemical Cycles 16(4): 61-1.

Grimm R, Behrens T, Märker M, Elsenbeer H. 2008. Soil organic carbon concentrations and stocks on Barro Colorado Island-Digital soil mapping using Random Forests analysis. Geoderma 146(1):102-113.

Hengl T, Heuvelink G, Stein A. 2004. A Generic Framework for Spatial Prediction of Soil Variables Based on Regression Kriging. Geoderma 122(1-2):75-93.

Huang H, Cheng X, Li B, Liu Y. 2007. Application of High-Resolution Remote Sensing Image Using ENVI. Geospatial Information 3.

Hudson BD. 1992. The soil survey as paradigm-based science. Soil Science Society of America Journal 56: 836-841.

PeerJ reviewing PDF | (2019:11:43319:2:0:NEW 11 Apr 2020) 
582

583

584

585

586

587

588

589

590

591

592

593

594

595

596

597

598

599

600

601

602

603

604

605

606

607

608

609

610

611

612

613

614

615

616

617

618

619

620

621

Lettens S, Van Orshoven J, van Wesemael B, Muys B. 2004. Soil organic and inorganic carbon contents of landscape units in Belgium derived using data from 1950 to 1970. Soil Use and Management 20(1): 40-47.

Jaeger JAG. 2000. Landscape division, splitting index, and effective mesh size: new measures of landscape fragmentation. Landscape ecology 15(2):115-130.

Jenny H. 1941. Factors of Soil Formation. McGraw-Hill, New York.

Jobbagy EG, Jackson RB. 2000. The vertical distribution of soil organic carbon and its relation to climate and vegetation. Ecological applications 10: 423-436.

Kieft TL, White CS, Loftin SR, Aguilar R, Craig J, Skaar DA. 1998. Temporal dynamics in soil carbon and nitrogen resources at a grassland-shrubland ecotone. Ecology 79(2): 671-683.

Kovačević M, Bajat B, Gajić B. 2010. Soil type classification and estimation of soil properties using support vector machines. Geoderma 154(3):340-347.

Kumar S., Lal R., Liu, D. 2012. A geographically weighted regression kriging approach for mapping soil organic carbon stock. Geoderma, 189, 627-634.

Kunkel ML, Flores AN, Smith TJ, McNamara JP, Benner SG. 2011. A simplified approach for estimating soil carbon and nitrogen stocks in semi-arid complex terrain. Geoderma 165(1):1-11.

Lal R. 2004. Soil carbon sequestration impacts on global climate change and food security. Science 304 (5677):1623-1627 (2004).

Liu F, Rossiter D-G, Song XD, Zhang GL, Yang RM, Zhao YG, Ju B. 2016. A similaritybased method for three-dimensional prediction of soil organic matter concentration. Geoderma 263: 254-263.

Liu J. 2010. Mapping Soil Properties Using Individual Representativeness of Samples over Large Area. Beijing, Beijing Normal University. (in Chinese).

Matejovic I. 1993. Determination of carbon, hydrogen, and nitrogen in soils by automated elemental analysis (dry combustion method). Communications in Soil Science and Plant Analysis 24(17-18): 2213-2222.

McBratney AB, Santos MLM, Minasny B. 2003. On digital soil mapping. Geoderma 17: 3-52. Minasny B., Malone B.P., McBratney A.B., Angers D.A., Arrouays D., Chambers A., Field D.J. 2017. Soil carbon 4 per mille. Geoderma 292, 59-86.

Minasny B, McBratney AB. 2008. Regression rules as a tool for predicting soil properties from infrared reflectance spectroscopy. Chemometrics and intelligent laboratory systems 94(1): 7279.

Minasny B., McBratney A.B., Malone B.P., Wheeler, I. 2013. Digital mapping of soil carbon. In Advances in Agronomy. Academic Press 118, 1-47.

Mondal A, Khare D, Kundu S, Mondal S, Mukherjee S, Mukhopadhyay A. 2017. Spatial soil organic carbon (SOC) prediction by regression kriging using remote sensing data. The Egyptian Journal of Remote Sensing and Space Science 20(1), 61-70.

Moore ID, Gessler PE, Nielsen GAE, Peterson GA. 1993. Soil attribute prediction using terrain analysis. Soil science society of america journal 57(2): 443-452.

PeerJ reviewing PDF | (2019:11:43319:2:0:NEW 11 Apr 2020) 
622

623

624

625

626

627

628

629

630

631

632

633

634

635

636

637

638

639

640

641

642

643

644

645

646

647

648

649

650

651

652

653

654

655

656

657

658

659

660

661

Mulder VL, Lacoste M, Richer-de-Forges AC. 2016. National versus global modelling the 3D distribution of soil organic carbon in mainland France. Geoderma 263: 16-34.

Odeh IOA, McBratney AB, Chittleborough DJ. 1995. Further Results on Prediction of Soil Properties from Terrain Attributes: Heterotopic Cokriging and Regression-Kriging. Geoderma 67:215-226.

Peilin L, Chunla L, Yunyuan D, Xiuying SHEN, Bohua LI, Zui HU. 2010. Landscape division of traditional settlement and effect elements of landscape gene in China. Acta Geographica Sinica 65(12): 1496-1506.

Post WM, Kwon KC. 2000. Soil carbon sequestration and land-use change: processes and potential. Global change biology 6:317-327.

R Development Core Team. 2013. R: A language and environment for statistical computing. Vienna, Austria; R Foundation for Statistical Computing.

Rial M, Cortizas AM, Taboada T, Rodríguez-Lado L. 2017. Soil organic carbon stocks in Santa Cruz Island, Galapagos, under different climate change scenarios. Catena 156, 74-81.

Rosenbloom NA, Harden JW, Neff JC, Schimel DS. 2006. Geomorphic control of landscape carbon accumulation. Journal of Geophysical Research: Biogeosciences 111: (G1).

Scull P., Franklin J., Chadwick O.A., McArthur D. 2003. Predictive soil mapping: a review. Progress in Physical Geography 27(2): 171-197.

Schad P, Van Huyssteen C, Micheli E. 2014. International Soil Classification System for Naming Soils and Creating Legends for Soil Maps; World Reference Base for Soil Resources: Rome, Italy. 106:246-385.

Shi X, Zhu AX, Burt JE, Qi F, Simonson D. 2004. A case-based reasoning approach to fuzzy soil mapping. Soil Science Society of America Journal 68(3):885-894.

Song XD, Brus DJ, Liu F, Li DC, Zhao YG, Yang JL, Zhang GL. 2016. Mapping soil organic carbon content by geographically weighted regression: A case study in the Heihe River Basin, China. Geoderma 261: 11-22.

Stevens A, Udelhoven T, Denis A, Tychon B, Lioy R, Hoffmann L, Van Wesemael B. 2010. Measuring soil organic carbon in croplands at regional scale using airborne imaging spectroscopy. Geoderma 158(1):32-45.

Taghizadeh-Mehrjardi R, Minasny B, Sarmadian F, Malone BP. 2014. Digital mapping of soil salinity in Ardakan region, central Iran. Geoderma 213:15-28.

Tesfaye MA, Bravo F, Ruiz-Peinado R, Pando V, Bravo-Oviedo A. 2016. Impact of changes in land use, species and elevation on soil organic carbon and total nitrogen in Ethiopian Central Highlands. Geoderma 261:70-79

Wang K, Zhang C, Li W. 2013. Predictive mapping of soil total nitrogen at a regional scale: a comparison between geographically weighted regression and cokriging. Applied Geography 42:73-85.

Wang S, Adhikari K, Wang Q, Jin X, Li, H. 2018a. Role of environmental variables in the spatial distribution of soil carbon $(\mathrm{C})$, nitrogen $(\mathrm{N})$, and $\mathrm{C}: \mathrm{N}$ ratio from the northeastern coastal agroecosystems in China. Ecological indicators 84: 263-272. 
662 Wang S, Wang Q, Adhikari K, Jia S, Jin X, Liu H. 2016. Spatial-Temporal Changes of Soil

663

664

665

666

667

668

669

670

671

672

673

674

675

676

677

678

679

680

681

682

683

684

685

686

687

688

689

690

691

692

693

694

695

696

697

698

699

700

Organic Carbon Content in Wafangdian, China. Sustainability. 8(11):1154.

Wang S, Zhuang Q, Wang Q, Jin X, Han C. 2017. Mapping stocks of soil organic carbon and soil total nitrogen in Liaoning Province of China. Geoderma 305: 250-263.

Wang S, Zhuang Q, Jia S, Jin X, Wang Q. 2018b. Spatial variations of soil organic carbon stocks in a coastal hilly area of China. Geoderma, 314, 8-19.

Were K, Bui DT, Dick ØB, Singh BR. 2015. A comparative assessment of support vector regression, artificial neural networks, and random forests for predicting and mapping soil organic carbon stocks across an Afromontane landscape. Ecological indicators 52: 394-403.

Xu Y, Smith SE, Grunwald S, Abd-EIrahman A, Wani SP, Nair VD. 2018. Estimating soil total nitrogen in smallholder farm settings using remote sensing spectral indices and regression kriging. Catena 163: 111-122.

Yang L, Huang C, Liu G, Liu J, Zhu A-X. 2015. Mapping soil salinity using a similarity-based prediction approach: a case study in Huanghe River Delta, China. Chinese geographical science 25(3):283-294.

Yang L, Qi F, Zhu AX, Shi JJ, An YM. 2016. Evaluation of Integrative Hierarchical Stepwise Sampling for Digital Soil Mapping. Soil Science Society of America Journal 80 (3):637-651.

Yang L, Zhu AX, Qi F, Qin CZ, Li BL, Pei T. 2013. An integrative hierarchical stepwise sampling strategy and its application in digital soil mapping. International Journal of Geographical Information Science 27(1): 1-23.

Yang RM, Rossiter DG, Liu F, Lu, Y, Yang F, Yang F. 2015. Predictive mapping of topsoil organic carbon in an Alpine environment aided by Landsat TM. PloS one 10(10):e0139042.

Yang RM, Zhang GL, Liu F, Lu YY, Yang F, Yang F, Li DC. 2016. Comparison of boosted regression tree and random forest models for mapping topsoil organic carbon concentration in an alpine ecosystem. Ecological indicators 60: 870-878.

Zhao MS, Zhang GL, Wu YJ, Li DC, Zhao Y-G. 2015. Driving forces of soil organic matter change in Jiangsu Province of China. Soil use and management 31(4):440-449.

Liang Z, Chen S, Yang Y, Zhou Y, Shi Z. 2019. High-resolution three-dimensional mapping of soil organic carbon in China: Effects of SoilGrids products on national modeling. Science of The Total Environment 685: 480-489.

Zhu AX, Liu J, Qin CZ, Zhang SJ, Chen YN, Ma XW. 2010. Soil property mapping over large areas using sparse ad-hoc samples. 19th World Congress of Soil Science, Soil Solutions for a ChangingWorld. the International Union of Soil Science, Brisbane, Australia (1-6 August 2010).

Zhu AX, Yang L, Li B, Qin C, English E, Burt JE, Zhou C. 2008. Purposive sampling for digital soil mapping for areas with limited data. In: Hartemink, A.E. (Ed.), Digital Soil Mapping With Limited Data. Springer 33-245.

Zhu AX. 1997. A similarity model for representing soil spatial information. Geoderma 77:217242.

PeerJ reviewing PDF | (2019:11:43319:2:0:NEW 11 Apr 2020) 


\section{Table $\mathbf{1}$ (on next page)}

Table 1

Table 1. Summary statistics of SOC, STN, and environmental variables at sampling points. 


\section{Tables}

2 Table 1. Summary statistics of SOC, STN, and environmental variables at sampling points

\begin{tabular}{|c|c|c|c|c|c|c|c|c|}
\hline Property & Description & Units & Minimum & Mean & Maximum & SD & Skewness & Kurtosis \\
\hline $\mathrm{SOC}$ & Level of organic carbon content in soil & $\mathrm{g} \mathrm{kg}^{-1}$ & 8.50 & 12.95 & 22.02 & 3.78 & 1.07 & 0.06 \\
\hline STN & Sum of various forms of nitrogen in soil & $\mathrm{g} \mathrm{kg}^{-1}$ & 0.57 & 0.85 & 1.49 & 0.23 & 0.81 & -0.31 \\
\hline NDVI & $\begin{array}{l}\text { The difference between near infrared and red band reflectance is divided by the sum of } \\
\text { their }\end{array}$ & index & 0.15 & 0.40 & 0.56 & 0.08 & -0.25 & 0.15 \\
\hline MAT & Mean annual temperature from 1980 to 2010 & Celsius degree & 9.5 & 10.39 & 10.91 & 0.26 & -1.29 & 1.80 \\
\hline MAP & Mean annual precipitation from 1980 to 2010 & $\mathrm{~mm}$ & 605.8 & 609.2 & 622.6 & 3.97 & 1.54 & 1.95 \\
\hline Elevation & Absolute vertical distance to geoid & $\mathrm{m}$ & 1 & 66.53 & 309 & 61.48 & 1.67 & 2.87 \\
\hline Slope gradient & Maximum rate of change between cells and neighbors & degree & 0 & 9.46 & 41.90 & 9.78 & 1.33 & 1.29 \\
\hline TWI & Calculates slope and specific catchment area based topographic wetness index & index & 2.33 & 5.04 & 10.13 & 1.87 & 0.89 & 0.52 \\
\hline
\end{tabular}

3 Note: SOC, soil organic carbon; STN, soil total nitrogen; TWI, topographic wetness index; MAP, mean annual precipitation; MAT, mean annual temperature; NDVI: Normalized

4 Difference Vegetation Index; and SD, Standard deviation. 


\section{Table 2 (on next page)}

Table 2

Table 2. Comparison of the performances of ISA, GWR, RK, and BRT models using MAE, RMSE, and $\mathrm{R}^{2}$ with validation Data in predicting SOC and STN. 
1 Table 2. Comparison of the performances of ISA, GWR, RK, and BRT models using MAE, RMSE, and $2 \mathrm{R}^{2}$ with validation Data in predicting SOC and STN.

\begin{tabular}{|c|c|c|c|c|c|}
\hline Property & Category & Item & MAE & RMSE & $\mathbf{R}^{2}$ \\
\hline \multirow{8}{*}{$\operatorname{SOC}\left(\mathrm{g} \mathrm{kg}^{-1}\right)$} & \multirow{4}{*}{ Classified } & ISA & 0.74 & 1.01 & 0.76 \\
\hline & & GWR & 0.96 & 2.35 & 0.57 \\
\hline & & RK & 1.12 & 2.87 & 0.48 \\
\hline & & BRT & 0.87 & 1.68 & 0.64 \\
\hline & \multirow{4}{*}{ Unclassified } & ISA & 0.98 & 1.34 & 0.54 \\
\hline & & GWR & 1.17 & 2.67 & 0.46 \\
\hline & & RK & 1.27 & 2.97 & 0.41 \\
\hline & & BRT & 1.05 & 2.13 & 0.51 \\
\hline \multirow{8}{*}{ STN $\left(\mathrm{g} \mathrm{kg}^{-1}\right)$} & \multirow{4}{*}{ Classified } & ISA & 0.03 & 0.04 & 0.83 \\
\hline & & GWR & 0.08 & 0.09 & 0.54 \\
\hline & & RK & 0.11 & 0.15 & 0.43 \\
\hline & & BRT & 0.06 & 0.07 & 0.67 \\
\hline & \multirow{4}{*}{ Unclassified } & ISA & 0.12 & 0.09 & 0.57 \\
\hline & & GWR & 0.13 & 0.16 & 0.41 \\
\hline & & RK & 0.15 & 0.19 & 0.38 \\
\hline & & BRT & 0.11 & 0.13 & 0.51 \\
\hline
\end{tabular}

3 Note: SOC, soil organic carbon; STN, soil total nitrogen; MAE, mean absolute prediction error; RMSE, root mean square error;

$4 \mathrm{R}^{2}$, coefficient of determination; GWR, geographically weighted regression; and RK, regression kriging (RK); BRT, boosted 5 regression trees. 


\section{Table 3 (on next page)}

Table 3

Table 3. Statistics of prediction performance and mean prediction results of each climatevegetation landscapes by ISA model. 
Table 3. Statistics of prediction performance and mean prediction results of each climate-vegetation landscapes by ISA model

\begin{tabular}{|c|c|c|c|c|c|c|c|c|}
\hline \multirow[b]{2}{*}{ Property } & \multirow[b]{2}{*}{ Index } & \multirow[b]{2}{*}{ Unit } & \multicolumn{6}{|c|}{ Climate-vegetation landscapes } \\
\hline & & & Coastal plain & Interior plain & $\begin{array}{l}\text { Medium-coverage } \\
\text { grasslands }\end{array}$ & $\begin{array}{l}\text { High-coverage } \\
\text { grasslands }\end{array}$ & $\begin{array}{l}\text { Low-elevation } \\
\text { forest }\end{array}$ & $\begin{array}{c}\text { Low-mountain } \\
\text { shrub }\end{array}$ \\
\hline \multirow{6}{*}{$\mathrm{SOC}$} & Observed & $\left(\mathrm{g} \mathrm{kg}^{-1}\right)$ & 9.11 & 11.04 & 11.29 & 12.38 & 14.41 & 20.02 \\
\hline & Predicted & $\left(\mathrm{g} \mathrm{kg}^{-1}\right)$ & 8.80 & 10.26 & 11.06 & 12.19 & 14.78 & 20.86 \\
\hline & $\mathrm{RD}$ & $(\%)$ & 3.40 & 7.07 & 2.04 & 1.53 & -2.57 & -4.20 \\
\hline & MAE & $\left(\mathrm{g} \mathrm{kg}^{-1}\right)$ & 0.31 & 0.81 & 0.28 & 0.58 & 1.44 & 0.84 \\
\hline & RMSE & (g kg-1) & 0.14 & 1.56 & 0.13 & 0.46 & 2.53 & 0.82 \\
\hline & $\mathrm{R}^{2}$ & & 0.64 & 0.77 & 0.6 & 0.55 & 0.49 & 0.37 \\
\hline \multirow{6}{*}{ STN } & Observed & $\left(\mathrm{g} \mathrm{kg}^{-1}\right)$ & 0.61 & 0.72 & 0.76 & 0.83 & 0.99 & 1.22 \\
\hline & Predicted & $\left(\mathrm{g} \mathrm{kg}^{-1}\right)$ & 0.59 & 0.69 & 0.76 & 0.81 & 1 & 1.27 \\
\hline & $\mathrm{RD}$ & $(\%)$ & 3.28 & 4.17 & 0.00 & 2.41 & -1.01 & -4.10 \\
\hline & MAE & $\left(\mathrm{g} \mathrm{kg}^{-1}\right)$ & 0.03 & 0.04 & 0.01 & 0.03 & 0.03 & 0.05 \\
\hline & RMSE & $\left(\mathrm{g} \mathrm{kg}^{-1}\right)$ & 0.01 & 0.04 & 0.01 & 0.02 & 0.06 & 0.02 \\
\hline & $\mathrm{R}^{2}$ & & 0.76 & 0.82 & 0.89 & 0.5 & 0.89 & 0.39 \\
\hline
\end{tabular}

Note: SOC, soil organic carbon; STN, soil total nitrogen; RD, relative difference; MAE, mean absolute prediction error; RMSE, root mean square error; $\mathrm{R}^{2}$, coefficient of determination. 


\section{Table 4 (on next page)}

Table 4

Table 4. Summary statistics of soil organic carbon (SOC) and soil total nitrogen (STN) prediction in different climate-vegetation landscapes using the ISA method based on 38 independent validation points. 
1 Table 4. Summary statistics of soil organic carbon (SOC) and soil total nitrogen (STN) prediction in different 2 climate-vegetation landscapes using the ISA method based on 38 independent validation points.

\begin{tabular}{cccccc}
\hline & $\begin{array}{c}\text { Number of } \\
\text { independent }\end{array}$ & \multicolumn{2}{c}{ SOC $\left(\mathbf{g ~ k g ~}^{-1}\right)$} & & STN $\left(\mathbf{g ~ k g ~}^{-1}\right)$ \\
\cline { 3 - 6 } Climate-vegetation landscapes & $\begin{array}{c}\text { Range of } \\
\text { validation } \\
\text { points }\end{array}$ & change & Mean \pm SD & Range of change & Mean \pm SD \\
& 5 & $0.85-17.64$ & $6.97 \pm 5.47$ & $0.34-1.13$ & $0.63 \pm 0.62$ \\
\hline Coastal plain & 7 & $2.38-33.98$ & $9.68 \pm 6.69$ & $0.43-1.32$ & $0.8 \pm 0.69$ \\
Interior plain & 6 & $7.61-29.74$ & $11.12 \pm 6.32$ & $0.74-2.07$ & $0.88 \pm 0.67$ \\
Medium-coverage grasslands & 7 & $8.04-33.25$ & $12.14 \pm 6.91$ & $0.77-2.28$ & $0.94 \pm 0.7$ \\
High-coverage grasslands & 8 & $10.24-33.8$ & $16.84 \pm 6.14$ & $0.9-2.31$ & $1.22 \pm 0.66$ \\
Low-elevation forest & 5 & $7.32-26.33$ & $11.49 \pm 5.34$ & $0.73-1.86$ & $0.91 \pm 0.61$ \\
\hline Low-mountain shrub & & & & &
\end{tabular}

3 Note: SD, Standard deviation.

4 
Figure 1

Figure 1

Fig 1. Location of the study area and 126 sampling sites (c) in Liaoning Province (b), China (a), which are shown superimposed on a 30-m resolution digital elevation model.
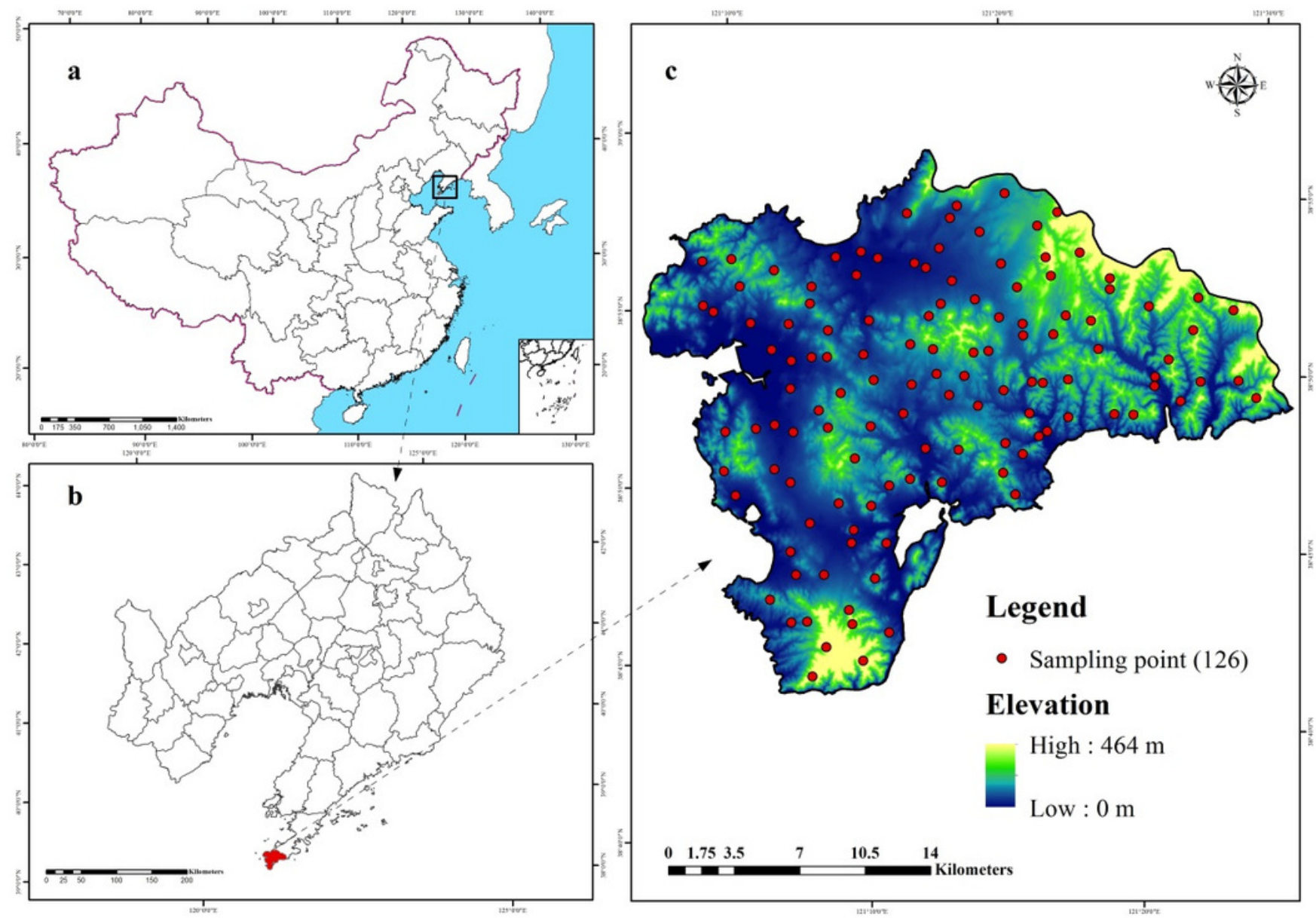


\section{Figure 2}

Figure 2

Fig 2. Climate-vegetation landscapes in the study area: Landscape 1, coastal plain; Landscape 2, interior plain; Landscape 3, medium-coverage grasslands; Landscape 4, highcoverage grasslands; Landscape 5, low-elevation forest; Landscape 6, low-mountain shrub.

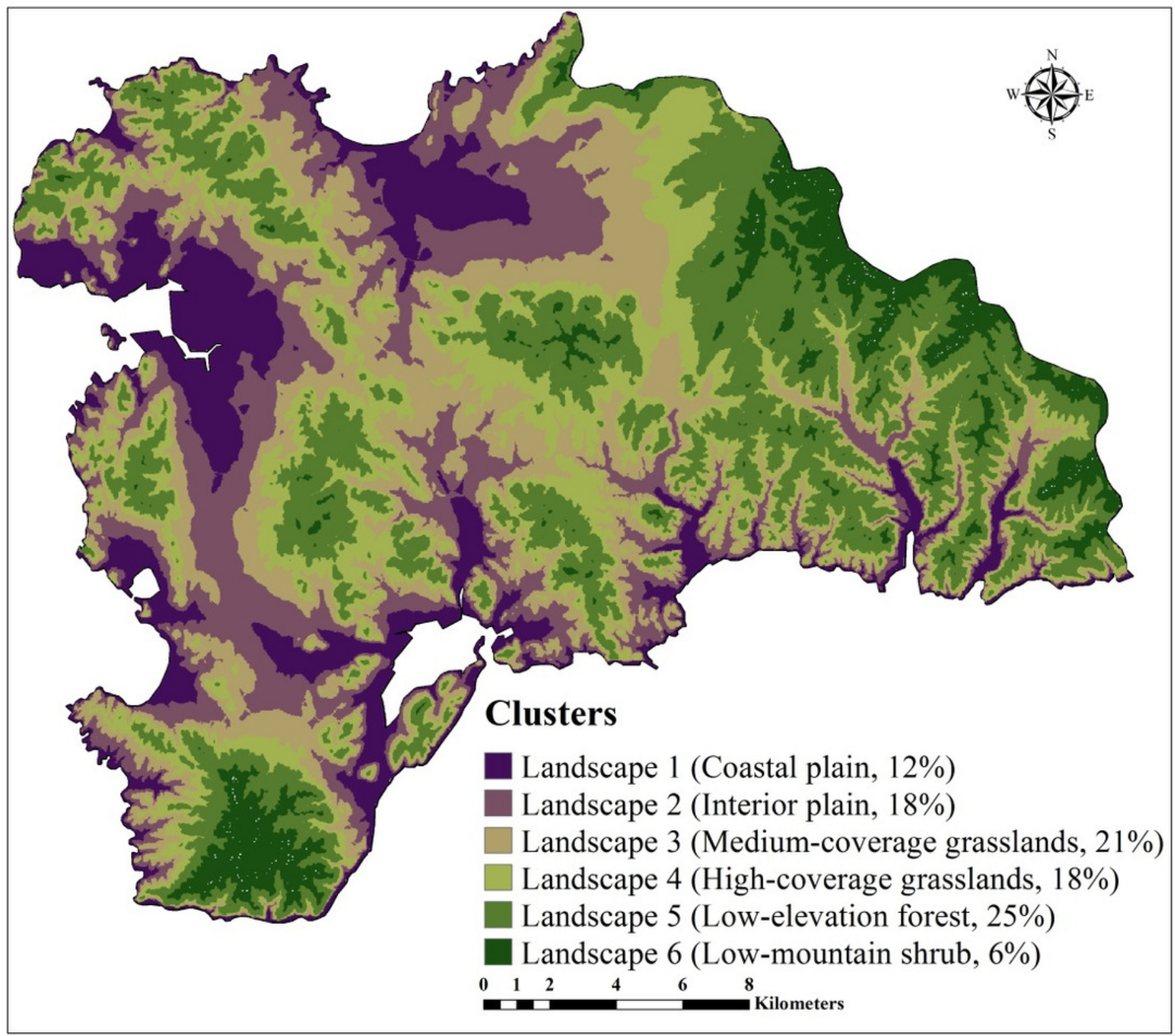


Figure 3

Figure 3

Fig 3. Flowchart of the methodology adopted in the study.

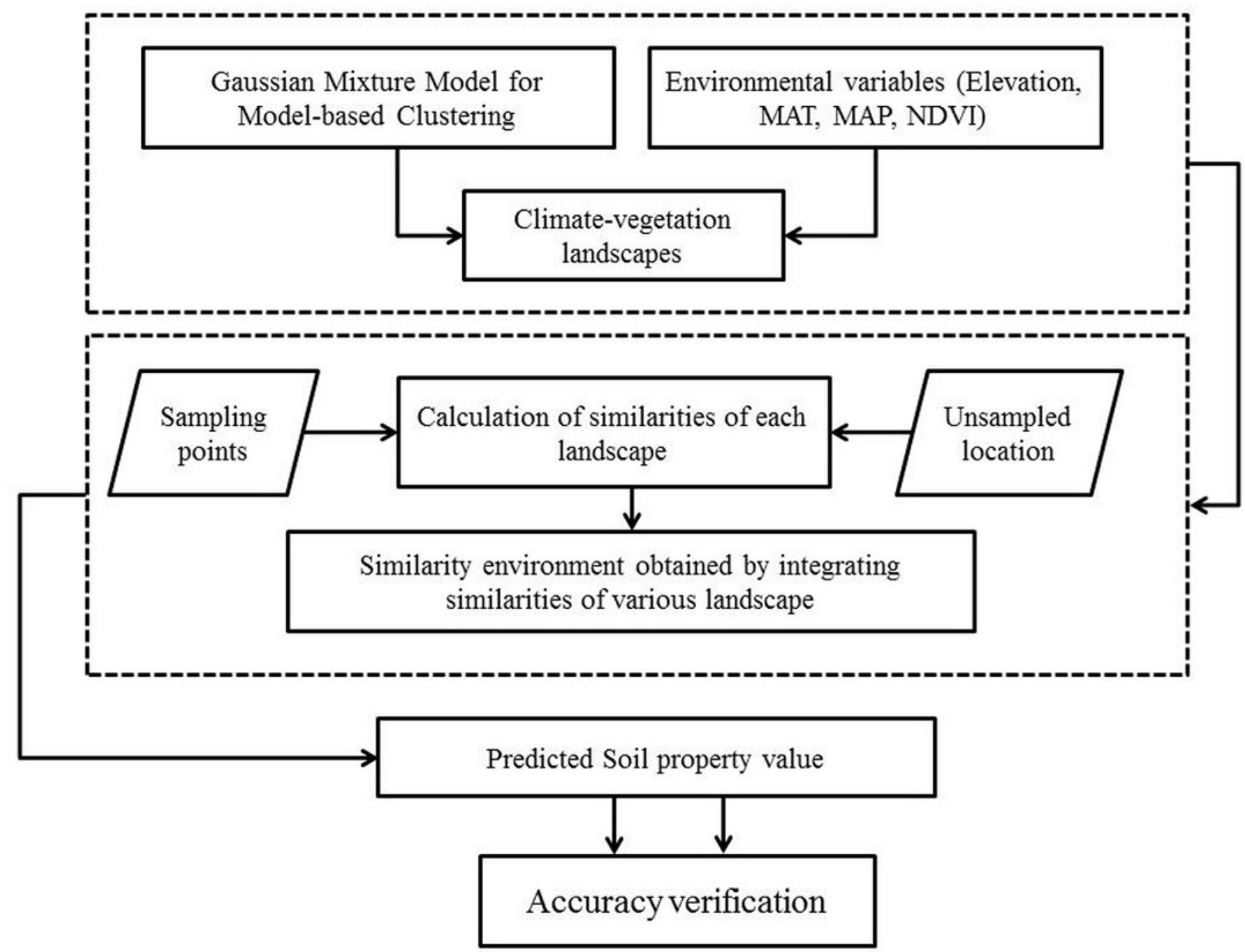


Figure 4

Figure 4

Fig 4. Pearson correlation coefficients of SOC and STN with environmental variables: SOC, soil organic carbon; STN, soil total nitrogen; TWI, topographic wetness index; SG, slope gradient; MAP, mean annual precipitation; MAT, mean annual temperature; and NDVI: Normalized Difference Vegetation Index.

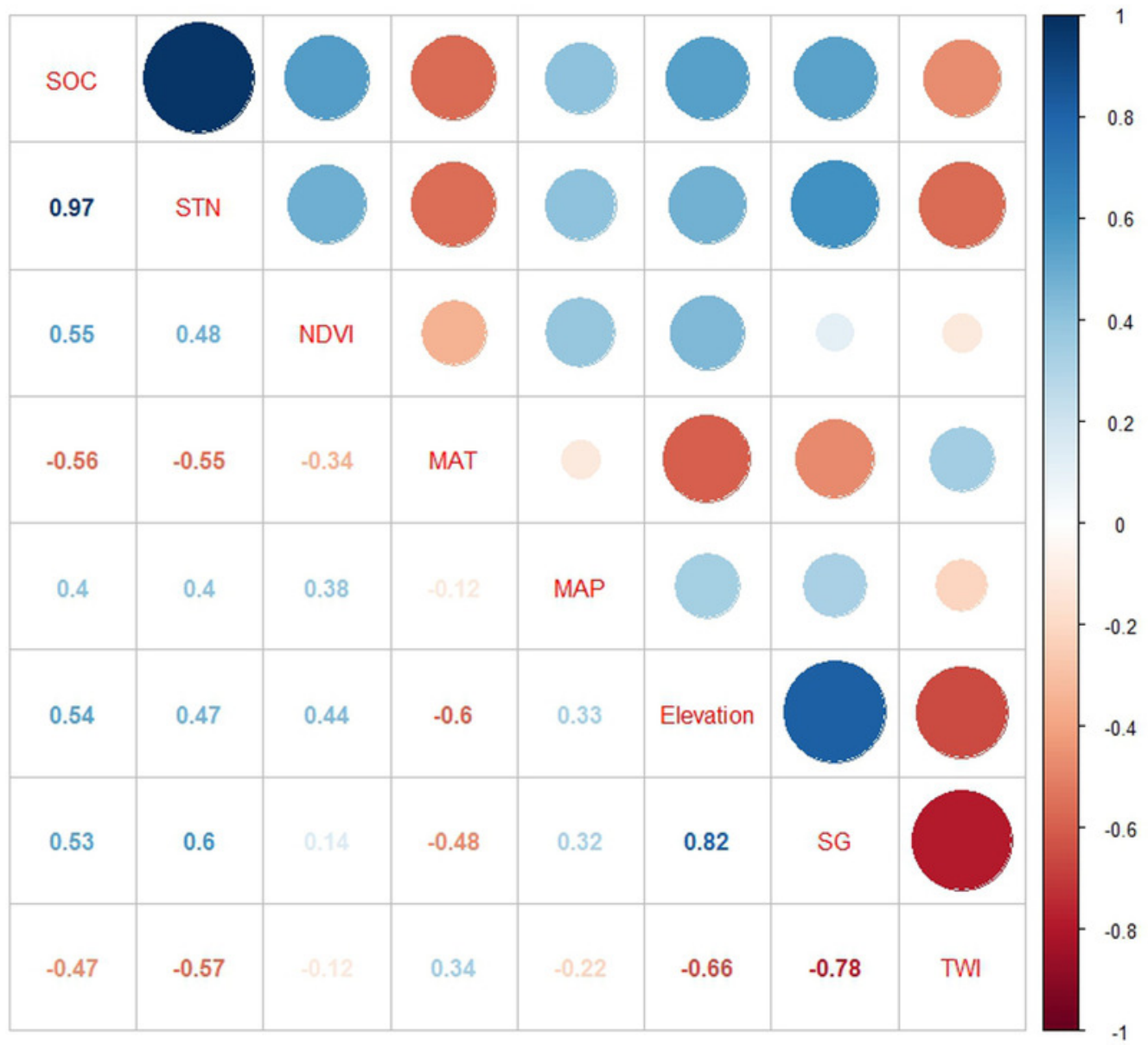




\section{Figure 5}

Figure 5

Fig 5. Boxplots of main environmental features related (elevation (a), mean annual precipitation (MAP) (b), mean annual temperature (MAT) (c), and normalized difference vegetation index (NDVI)) to climate-vegetation landscapes including CP: coastal plain; IP: interior plain; MCG: medium-coverage grasslands; HCG: high-coverage grasslands; LEF: lowelevation forest; and LMS: low-mountain shrub. Red is the training dataset $(n=88)$ and green is the independent verification dataset $(n=38)$. 


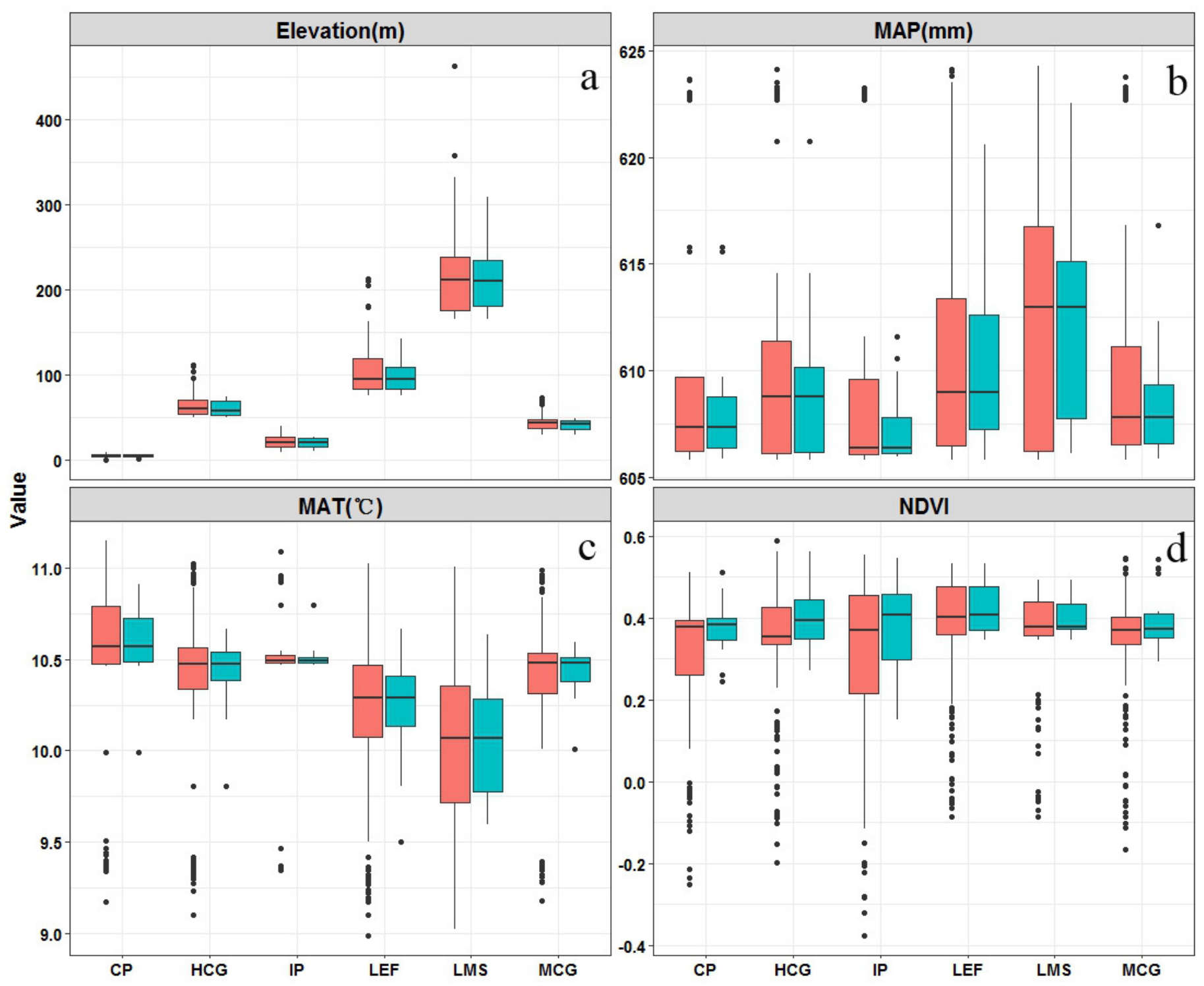


Figure 6

Figure 6

Fig 6. Scatter plot between the observed soil organic carbon (SOC) (a) and soil total nitrogen (STN) (b) content with its predicted values using the ISA model based on independent validation samples.
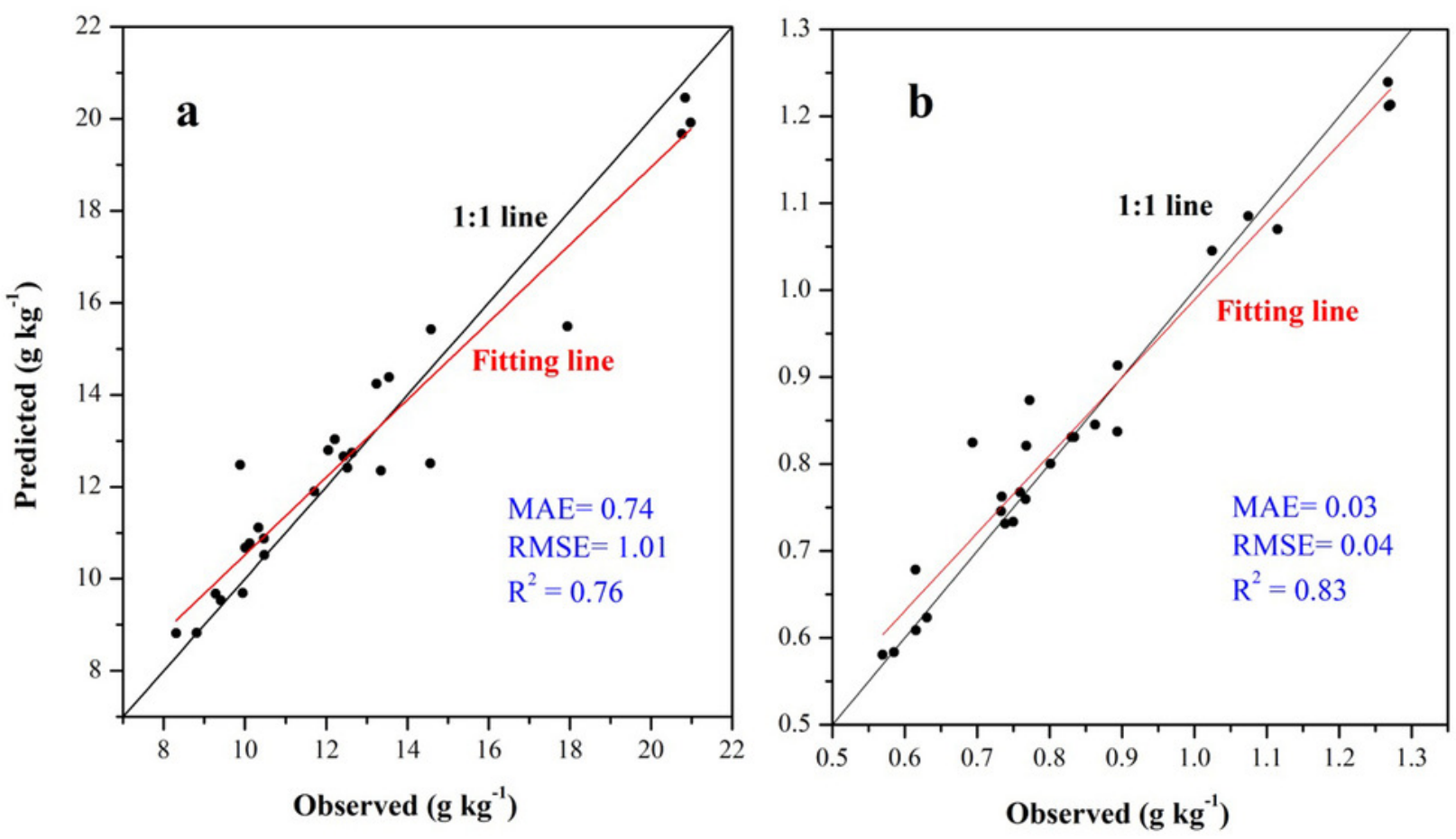


\section{Figure 7}

Figure 7

Fig 7. Prediction consistency map of $\mathrm{SOC}(\mathrm{a})$ and STN (b) and spatial distribution of SOC (g $\left.\mathrm{kg}^{-1}\right)$ (a) and STN $\left(\mathrm{g} \mathrm{kg}^{-1}\right)$ (b) predicted using an improved similarity-based approach (ISA).
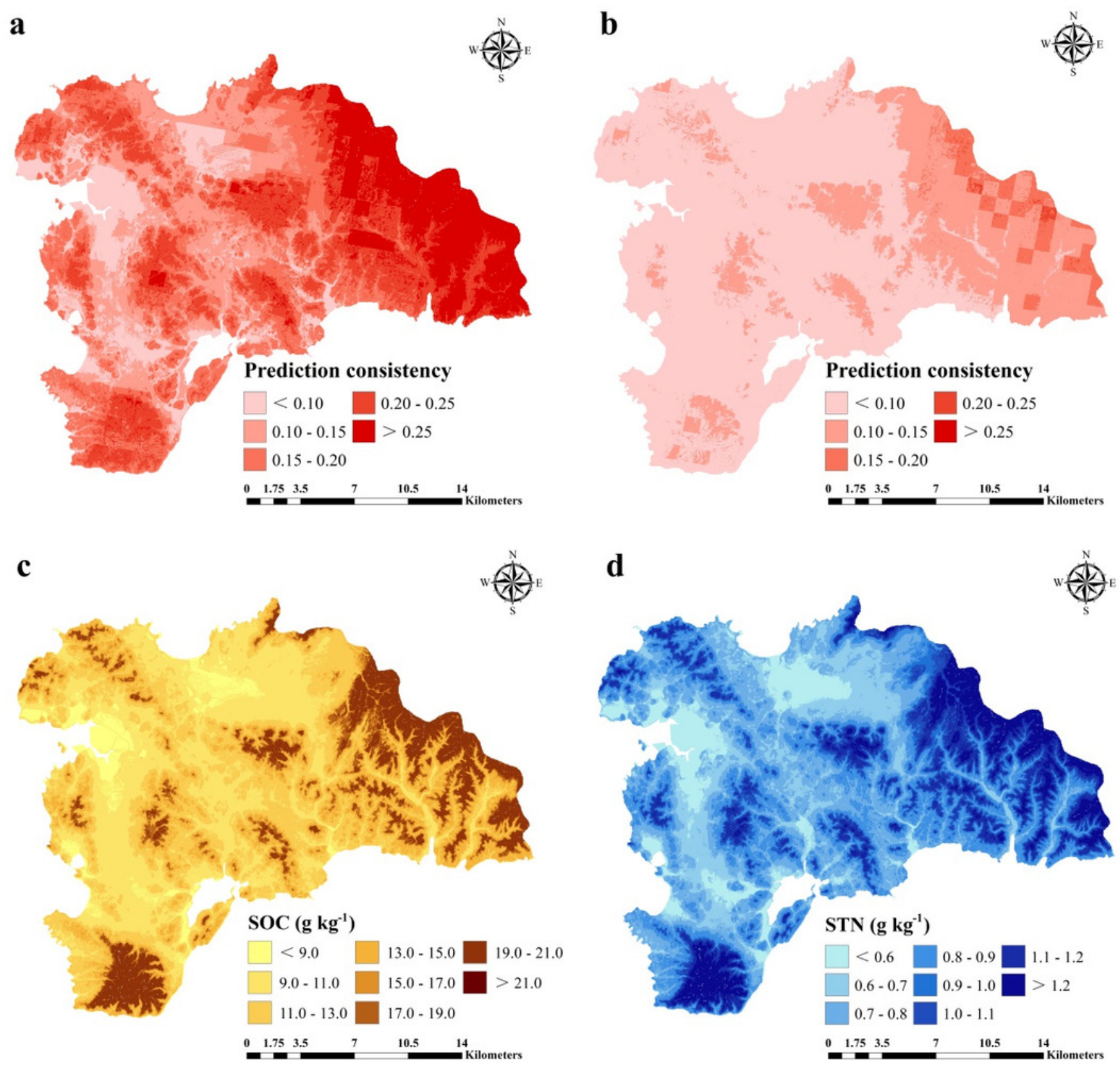


\section{Figure 8}

Figure 8

Figure 8. Relative importance of each variable as determined from the boosted regression trees (BRT) model in predicting soil organic carbon (SOC) (a) and soil total nitrogen (STN) (b).
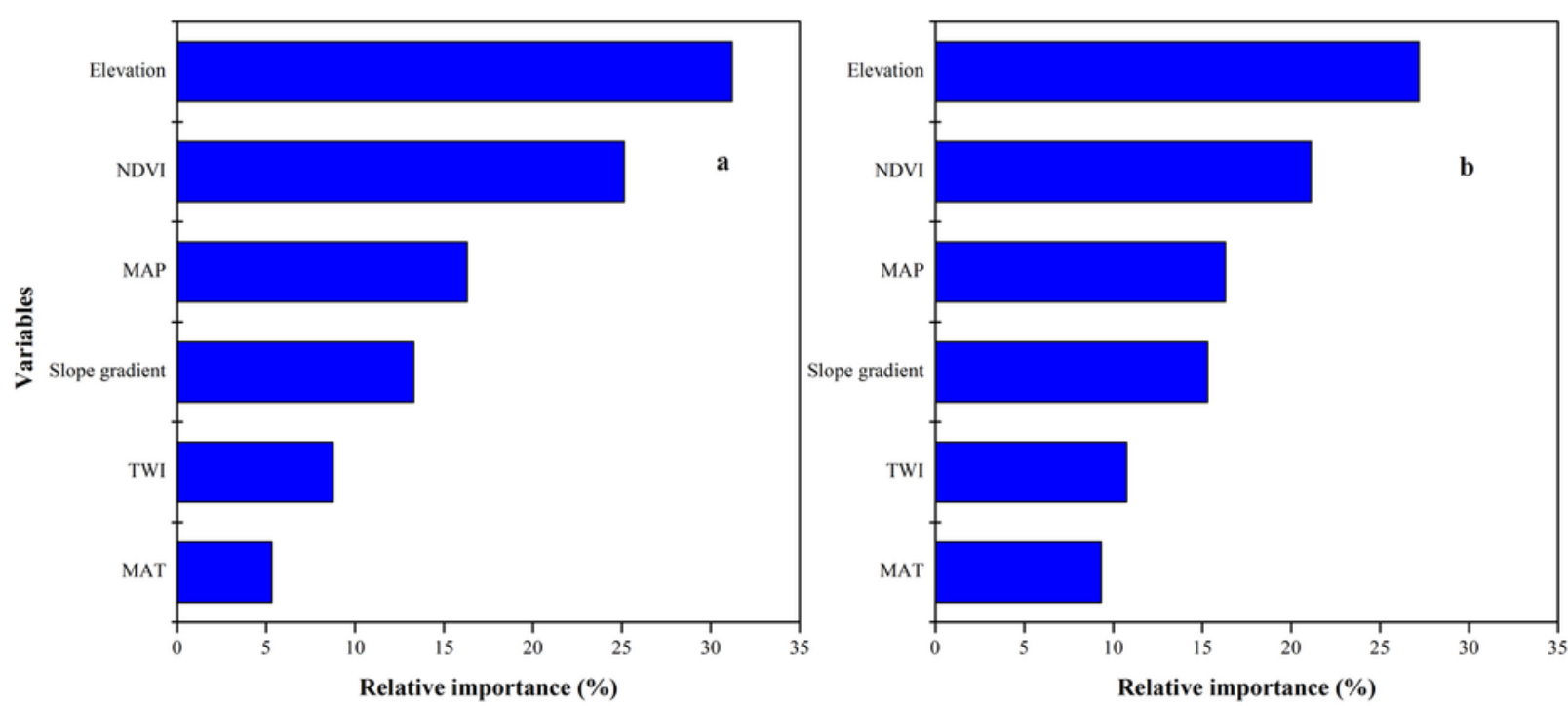